\title{
Ectopic expression of MITF, a gene for Waardenburg syndrome type 2, converts fibroblasts to cells with melanocyte characteristics
}

\author{
Masayoshi Tachibana ${ }^{1}$, Kazuhisa Takeda ${ }^{1}$, Yoshitaka Nobukuni ${ }^{2,5}$, Kazunori Urabe ${ }^{3,6}$, \\ Jason E. Long ${ }^{4}$, Kimberly A. Meyers ${ }^{4,7}$, Stuart A. Aaronson ${ }^{4,7}$ \& Toru Miki ${ }^{4}$
}

${ }^{1}$ Laboratory of

Molecular Genetics,

National Institute

on Deafness and

Other

Communication

Disorders, NIH, 5

Research Court,

Rockville, Maryland 20850, USA

${ }^{2}$ Clinical

Neurogenetics

Branch, National

Institute of Mental

Health, Bethesda

Maryland 20892,

USA

${ }^{3}$ Laboratory of Cell Biology, National

Cancer Institute,

Bethesda, Maryland

20892, USA

${ }^{4}$ Laboratory of

Cellular and

Molecular Biology,

National Cancer

Institute, Bethesda,

Maryland 20892,

USA

${ }^{5}$ Current address:

Department of

Inherited Metabolic

Diseases, National

Institute of

Neuroscience, Tokyo

187, Japan

${ }^{6}$ Current address:

Department of

Dermatology,

Shinkokura

Hospital,

Kitakyushu 802,

Japan

${ }^{7}$ Current address:

Derald $H$.

Ruttenberg Cancer

Center, The Mount

Sinai Hospital, New

York, 10029, USA

Correspondence

should be addressed

to M.T.

e-mail:mtachiba@

pop.nidcd.nih.gov

MITF (microphthalmia-associated transcription factor) encodes a transcription factor with a basic-helix-loop-helix-zipper (bHLH-Zip) motif. MITF mutations occur in patients with Waardenburg syndrome type 2 , a disorder associated with melanocyte abnormalities. Here we show that ectopic expression of MITF converts NIH/3T3 fibroblasts into cells with characteristics of melanocytes. MITF transfectants formed foci of morphologically altered cells, which resemble those induced by oncogenes, but did not exhibit malignant phenotypes. Instead, they contained dendritic cells that express melanogenic marker proteins such as tyrosinase and tyrosinase-related protein 1. Most cloned cells of MITF transfectants exhibited dendritic morphology and expressed melanogenic markers, but such properties were not observed in celis transfected with closely related TFE3 CDNA. Our findings indicate that MITF is critically involved in melanocyte differentiation.

Although some molecules such as Steel factor and its receptor are known to be involved in survival and/or proliferation of melanocytes, the molecular mechanisms of melanocyte differentiation were not well understood until the mouse gene for the microphthalmia ( $m i)$ locus, was identified. Dermal, cochlear and ocular melanocytes are known to differentiate from their precursor cells in the neural crest and/or the eye anlage. Hence, disruption of the genes involved in melanocyte differentiation predicts phenotypes related to pigmentary anomaly of skin, ear and eye. Indeed, mutations in several $m i$ alleles have been characterized ${ }^{1,2}$ : typical phenotypes of mice with homozygous mi mutations include white coat colour, small eye and hearing impairment $t^{3,4}$, each of which has been attributed to melanocyte depletion in the affected organs ${ }^{4}$. Therefore, $m i$ is most likely involved in melanocyte differentiation in mice.

As these mouse phenotypic changes are reminiscent of those observed in a subset of individuals with Waardenburg syndrome (WS) type 2 (WS2), mice with mutations at the mi locus represent a valuable animal model of this syndrome ${ }^{5}$. WS is a hereditary auditory-pigment syndrome showing clinical and genetic heterogeneity ${ }^{6}$. Persons with WS type 1 (WS1; ref. 7) have dystopia canthorum $^{6}$, an outward displacement of the inner canthi of eyes, which is not observed in individulas with WS2. WS is occasionally associated with other abnormalities ${ }^{8}$, such as anomalies in the musculoskeletal system of the limb (Klein-WS or WS3; ref. 9) or Hirschsprung disease (Waardenburg-Shah syndrome or WS4; ref. 10). Lossof-function mutations of a paired box and homeobox gene, PAX3, have been found in WS1 and WS3 (refs 11-16). Individuals with WS2 have symptoms which include white patches of the skin, pigmentary disturbances of iris and deafness, but do not show dystopia canthorum. Thus, in contrast with other types of WS, all WS2 symptoms may be explained by melanocyte depletion, the phenotype found in mice with loss-of-function mutations at the mi locus.

While mutations of $P A X 3$ were not found in WS2 (ref. 17), mutations of the MITF (microphthalmia-associated transcription factor) gene ${ }^{16,18,19}$, the human homologue of mouse $m i^{20}$, are associated with affected members of a subset (WS2A) of WS2 families $16,18,19$. MITF and $m i$ encode proteins with the basic-helix-loop-helix leucine zipper (bHLH-Zip) motif ${ }^{1,20}$. As mice with mutations at $m i$ alleles and individuals with WS2 lack melanocytes in the affected organs $s^{4,21}$, we speculated that MITF could be involved in mediating melanocyte differentiation by functioning as a transcription factor. Here we demonstrate that stable transfection of $\mathrm{NIH} / 3 \mathrm{~T} 3$ cells with MITF induces melanocytic phenotypes.

\section{Morphological changes of M/TF transfectants}

We chose $\mathrm{NIH} / 3 \mathrm{~T} 3$ cells to examine the function of the MITF gene, as these embryonic fibroblasts are known to differentiate into myoblasts or adipocytes in response to ectopic expression of specific lineage determinating transcription factor genes ${ }^{22-24}$. Cells were transfected with an expression vector (pCEV27; ref. 25) containing MITF CDNA and, stable transfectants were selected with G-418. These stable transfectants contained refractile cells, often with dendritic processes, which resembled melanocytes (Fig. 1a). Although pigmented granules were not visible under a light microscope, expression of tyrosinase, an enzyme involved in melanin biosynthesis 

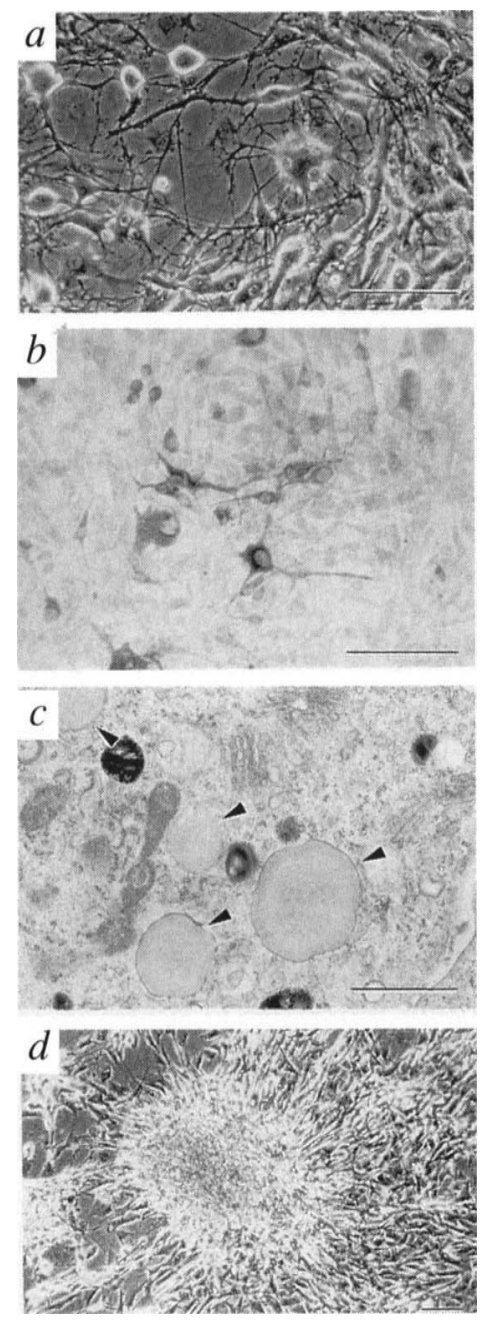

Fig. 1 Cytology of NIH/3T3 cells transfected with an MITF expression vector. a, A phase contrast micrograph of dendritic cells in MITF transfectants. $b$, Immunocytochemical detection of tyrosinase in MITF trans fectants. Dendritic cells in the transfectants are immunostained. c, Electron microscopic view of membrane-bound vesicles (arrowheads) in MITF transfectants. No such structure was observed in control vector-alone transfectants. d, A focus observed in MITF transfectants. Scale bars, $100 \mu \mathrm{m}$ for $a$ and $b$, and $50 \mathrm{~nm}$ for $c$. was observed using immunocytochemistry (Fig. 1b). Electron microscopic examination of these cells revealed membrane-bound vesicles with homogeneous matrices (Fig. 1c). Such structure is reminiscent of i) immature melanosomes, which are usually observed in albino animals, and ii) the structure observed in Swiss 3T3 cells and L cells transfected with tyrosinase $\mathrm{cDNA}^{26,27}$. The high electron density of membrane-bound vesicles in these cells transfected with tyrosinase CDNA is consistent with that of melanin ${ }^{26,27}$, while those of NIH/3T3 cells transfected with MITF cDNA showed lower electron density. Since $\mathrm{NIH} / 3 \mathrm{~T} 3$ cells, which are derived from Swiss mice $^{28}$, possess the mutated tyrosinase gene ${ }^{29}$, the vesicles in MITF transfectants are unlikely to contain melanin. Consistent with this notion, biochemical assays $^{30}$ did not detect significant activity of melanin synthesis in MITF transfectants (not shown) despite immunohistochemical evidence of tyrosinase protein expression (Fig. 1b).

\section{Induction of melanogenic marker proteins}

As MITF transfectants included cells morphologically similar to melanocytes, we examined expression of melanogenic markers known to be involved in melanin biosynthesis $^{31-33}$. Immunocytochemical analyses revealed the expression of tyrosinase (Fig. $1 b$ ) and TRP1 (not shown) in MITF tranfectants, notably in the dendritic cells. Therefore, expression of melanogenic marker proteins was analysed further by western blot analyses of MITF transfectants; three marker proteins: tyrosinase, tyrosinase-related protein 1 (TRP1) and TRP2, were expressed (Fig. 2a). Unexpectedly, TRP2 expression was also detected in vector transfectants, implicating that it is expressed constitutively in NIH/3T3 cells. Although the expression level of each protein in the

Fig. 2 Immunoblot detection of melanogenic markers. a, Immunoblot detection with antisera specific to tyrosinase ( $\alpha$ Tyr), tyrosinase related protein-1 ( $\alpha$ TRP1) or tyrosinase related protein-2 ( $\alpha$ TRP2) in lysates of MITF transfectants (M) and control vector transfectants $(C)$. Tyrosinase and TRP1 was detected as a single band (arrowheads) only in MITF transfectants, while TRP2 was observed in both MITF transfectants and vector alone transfectants. $b$, Expression of tyrosinase and TRP1 in MITF transfectansts was lower in culture of low density $(L)$ than of high density $(H)$. Sizes of proteins detected in MITF transfectants are as follows: tyrosinase $-69 \mathrm{kD}$; TRP1, $-69 \mathrm{kD}$; and TRP2, $\sim 67 \mathrm{kD}$. $c$, Effects of serum starvation on expression of tyrosinase (arrowhead) in MITF transfectants (pCEV27-MITF) and vector alone transfectants (pCEV27). Numbers at the top of each lane represent hours after the initiation of serum starvation. transfectants were less than that found in melanocytes or melanoma cells (not shown), these proteins were expressed consistently in independently isolated MITF transfectants. The low level of expression of these melanogenic marker proteins may be related to the finding that only a minor fraction (approximately $2 \%$ ) of MITF transfectant cells showed a melanocyte-like appearance. MITF transfection in the absence of marker selection led to the appearance of foci of morphologically altered cells which superficially resembled foci induced by oncogenes. However, MITF tranfectants did not exhibit the malignant phenotype. They failed to form colonies in soft agar and did not induce tumours in nude mice (not shown). Conversely, the expression of tyrosinase and TRP1 proteins was not induced by transfection of NIH/3T3 cells with several transforming (focus forming) genes, including $c-s i s$ and $o s t^{34}$ (data not shown), indicating that expression of these melanogenic markers could not be attributed to the focus forming activity of MITF.

We found that expression of tyrosinase and TRP1 induced by ectopic expression of MITF was influenced by culture conditions. When expression levels of these proteins were compared in low and high (confluent) density cultures, the levels of both marker proteins were higher in cells at saturation density than in growing cells (Fig. 2b). In contrast, the level of TRP2 was not influenced by the culture condition. Serum starvation increased expression of tyrosinase (Fig. $2 c$ ) and TRP1 (not shown) as early as 12 hours after initiation of starvation, and their expression remained elevated by several fold for at least 64 hours.

\section{Detection of melanogenic marker RNAs}

We detected expression of tyrosinase mRNAs in MITF transfectants by northern blot analysis, although it was lower than that in a mouse melanocyte cell line (melana) and a mouse melanoma cell line (B16F10) (Fig. 3a). Since the RNA expression levels of TRP1 and TRP2 were lower than that of tyrosinase in MITF transfectants, we utilized reverse transcription (RT)-PCR to detect TRPI and TRP2 mRNA expression. By this method, the expression of TRP1 was detected in MITF transfectants but not in control (vector alone) transfectants (Fig. $3 b$ ). In contrast, RNA expression of TRP2 was observed in both MITF transfectants and control transfectants (Fig. $3 b$ ), which agreed with immunoblot and immunocytochemical data (not shown), suggesting the constitutive expression of TRP2 in NIH/3T3 cells. Expression levels of TRPI and TRP2 mRNAs were lower than that of tyrosinase mRNA, while protein levels of tyrosinase,

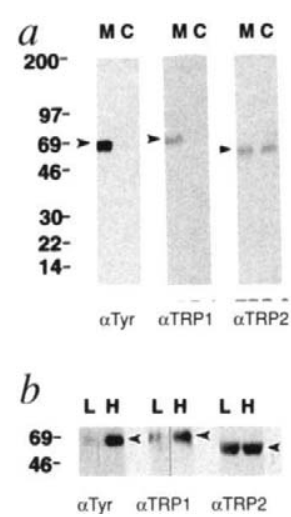

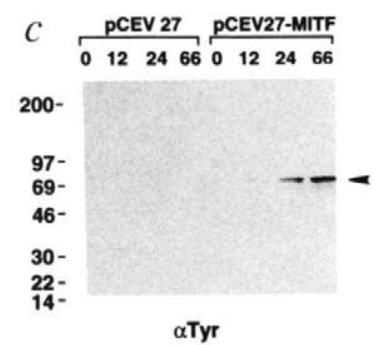

$\alpha \mathrm{Tyr}$ 

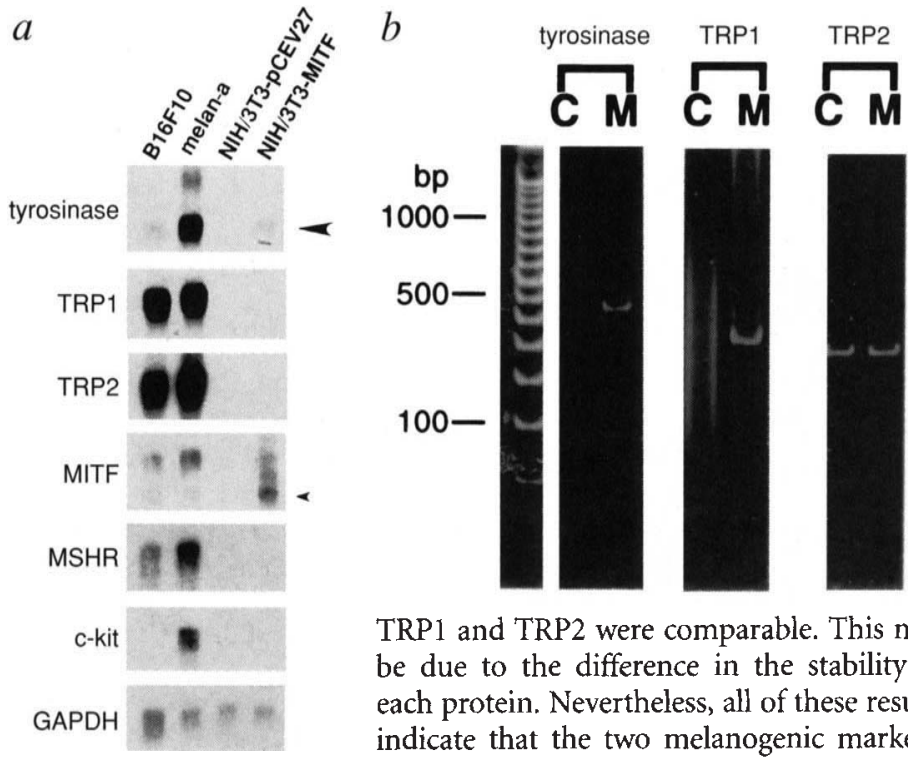

TRP1 and TRP2 were comparable. This may be due to the difference in the stability of each protein. Nevertheless, all of these results indicate that the two melanogenic markers, tyrosinase and TRP1, were induced specifically by $M I T F$ expression in NIH/3T3 cells.

\section{Related TFE3 lacks similar effects}

MITF protein is most closely related to three bHLH-Zip proteins; TFEB, TFE3, and TFEC ${ }^{35-37}$. Mi protein has been shown to bind DNA as a homodimer or heterodimer with these proteins ${ }^{38}$. To examine if these MITF-related bHLH-Zip proteins have functions similar to MITF, we transfected NIH/3T3 cells with TFE3 cDNA. In this series of experiments, we cloned the transfectants by a dilution method ${ }^{39}$. In four out of five clonal MITF cell lines, cells were dendritic in shape and resembled cultured mouse melanocytes (Fig. $4 a, b)$, while the remaining clonal cell line did not show such characteristics. Moreover, cells from these four clonal cell lines were immunostained for tyrosinase and TRP1, as were cultured melanocytes (Fig. $5 a, b, e, f$; the absorption test revealed that the antigen efficiently blocked the immunocytochemical detection (Fig. $5 a, e$, inset). In contrast to MITF transfectants, all of eleven clonal TFE3 cell lines failed to show such characteristics (Figs 4, 5), indicating that TFE3 is not capable of inducing melanocyte differentiation by itself.

\section{Discussion}

We have shown that transfection of MITF CDNA, which encodes a bHLH-Zip protein, can convert $\mathrm{NIH} / 3 \mathrm{~T} 3$ fibroblasts to cells with a melanocyte-like morphology. These cells also exhibit specific induction of
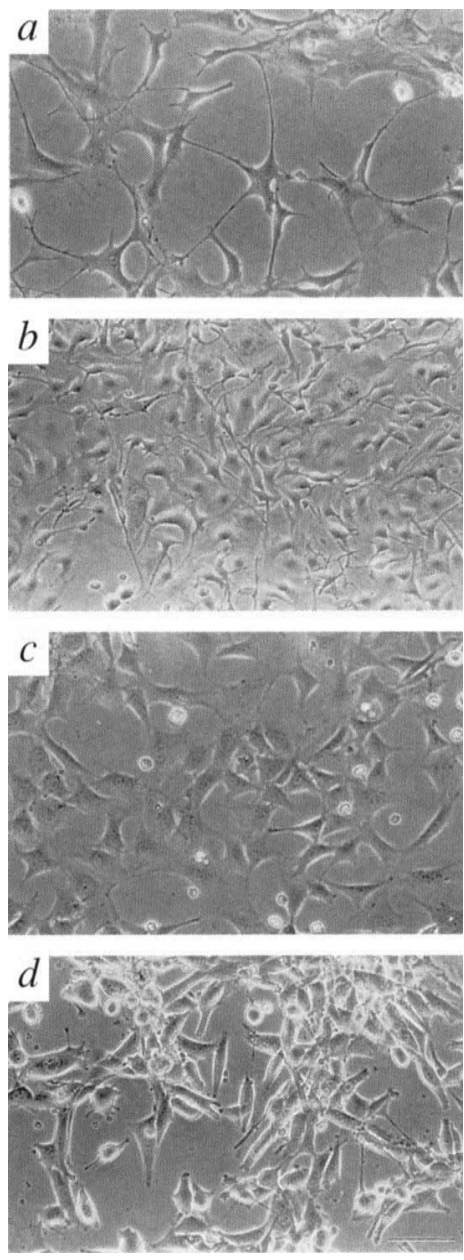

Fig. 4 Morphology of cloned transfectants $(a, c, d)$ and cultured mouse melanocytes (melan-a) (b). Note the dendritic cell shape of MITF transfectants (a) similar to that of melan-a cells (b). TFE3 transfectants $(c)$ and vector alone transfectants (d) did not show such the phenotype. Scale bar, $100 \mu \mathrm{m}$.
Fig. 3 RNA expression of melanogenic markers as detected by northern blotting (a) and RT-PCR (b). a, The tyrosinase and major MITF transcripts in cells transfected with MITF are indicated by large and small arrowheads, respectively. The size of transcripts detected in B16F10 and melan-a is as follows: tyrosinase, 6.6 and $2.1 \mathrm{~kb}$; TRP1, $2.6 \mathrm{~kb}$; TRP2, $2.4 \mathrm{~kb}$; MITF, $5.5 \mathrm{~kb}$; MSHR and GAPDH (glyceraldehyde-3-phosphate dehydrogenase), 1.7 kb. Induction of c-kit and MSHR by MITF transfection was not detected under these conditions. $b$, RT-PCR. The PCR products for tyrosinase, TRP1 and TRP2 were detected in MITF transfectants (M). The product for TRP2 was also detected in contro

melanogenic markers, tyrosinase and TRP1. As these cells did not show melanin synthesis despite of their melanocytic morphology and expression of melanogenic kers, they are similar to amelanotic melanocytes. melanocyte, and amelanotic melanocytes are functional least in the cochlea ${ }^{40,41}$. Therefore, it appears that In contrast, stable expression of TFE3 a ubiquitous protein structurally related to MITF ${ }^{35,38}$, in NIH/3T3 cells did not induce melanocytic phenotypes. Therefore, TFE3 itself is unlikely to be capable of inducing melanocytic differentiation.

Although the molecular mechanism for induction of dendritic morphology and melanogenic marker expression by ectopic expression of MITF needs to be clarified, the results of several biochemical studies are consistent with the induction of this phenotype. For example, reporter assays have revealed that transient expression of $\mathrm{Mi} / \mathrm{MITF}$ trans-activates promoters of the tyrosinase and TRP1 genes in $\mathrm{NIH} / 3 \mathrm{~T} 3$ cells $^{1,42-44}$. The increased expression of melanogenic marker proteins in MITF transfectants was achieved by depriving the transfectants of serum, which contains a number of growth factors, and may have biological implications. Growth and differentiation are usually mutually exclusive, and antagonism between these two states is observed in cultured melanocytes ${ }^{45}$ and melanoma cells $s^{46}$. Such antagonism is also seen in myogenic differentiation induced by the bHLH proteins of the myogenic gene family ${ }^{47}$.

The efficiency of induction of melanocytic differentiation by MITF seems to depend on the parental cell line, since we did not detect the expression of melanogenic markers in two other mouse cell lines (10T1/2 and L cell) transfected with MITF. At least two interpretations are possible for these observations. Variability of induction has been noted in the case of myogenic differentiation induced by the expression of myoD: the induction rate was higher in $10 \mathrm{~T} 1 / 2$ cells than in 

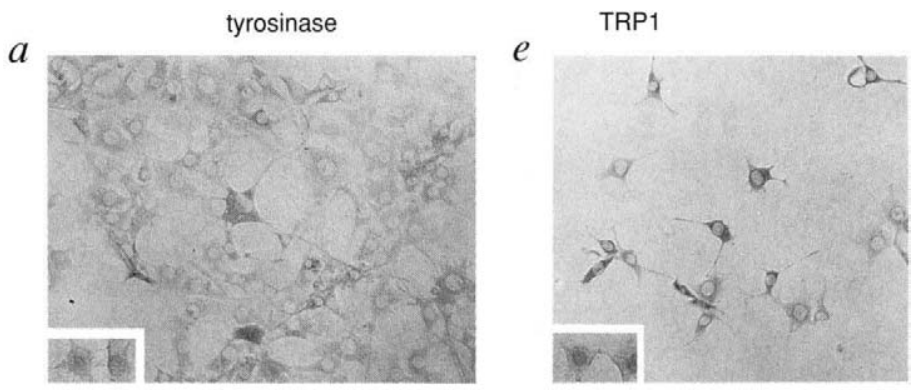

$b$
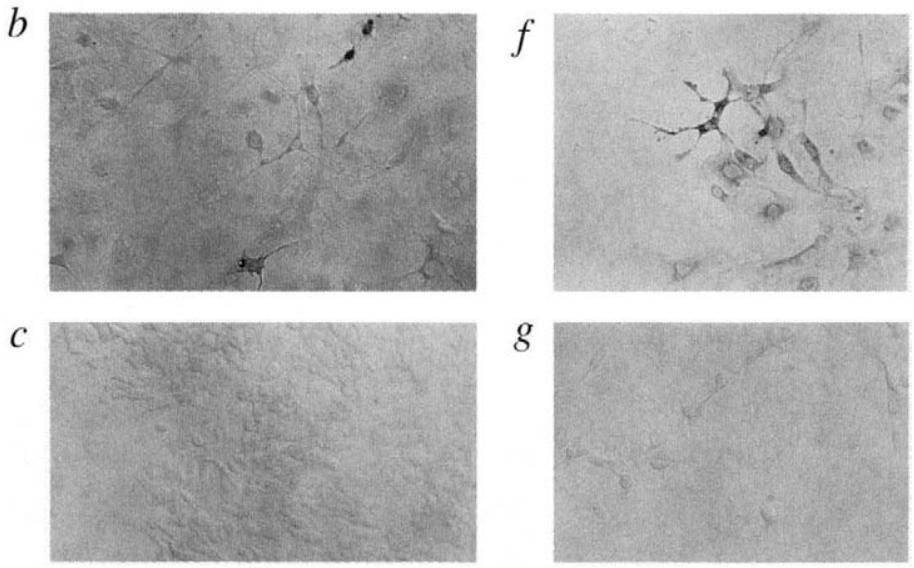

$d$
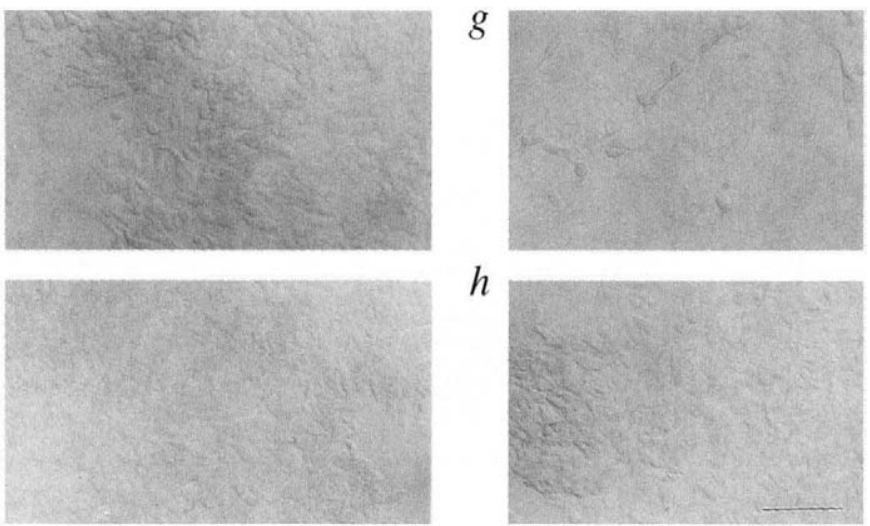

$h$

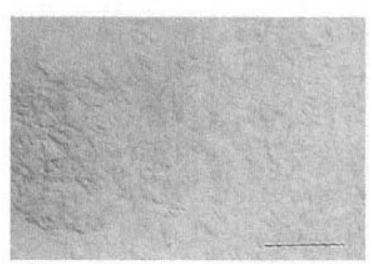

Fig. 5 Immunocytochemical detection of proteins of tyrosinase (a- $d$ ) and TRP1 $(e-h)$ in cloned transfectants and cultured mouse melanocytes (melan-a). immunostaining for both tyrosinase and TRP1 were observed in the cytoplasm of MITF clone $(a, e)$ as well as in that of melan-a cells $(b, f)$. Such staining was not observed when antisera, which was absorbed with each antigenic peptide, was used ( $a, e$; insets). In contrast to MITF transfectants, neither tyrosinase nor TRP1 was expressed in TFE3 clone $(c, g)$ and vector-alone transfectants $(d, h)$. Scale bar, $100 \mu \mathrm{m}$.

$\mathrm{NIH} / 3 \mathrm{~T} 3$ and $\mathrm{L}$ cells ${ }^{22}$. Interestingly, somatic cell hybrids between $10 \mathrm{~T} 1 / 2$ cells and karyotypically normal primary fibroblasts fail to induce myogenic conversion, while transfer of chromosome 11 , containing the $M y o D$ locus, into $10 \mathrm{~T} 1 / 2$ cells results in activation of $M y o D$ and myogenic conversion ${ }^{48}$. These studies have suggested that fibroblasts contain an active component capable of inhibiting myogenic differentiation by MyoD. Based on these observations, it was recently found that forced expression of a homeobox gene, MSX1, in $10 \mathrm{~T} 1 / 2$ cells which do not express this gene endogeneously, represses $M y o D$ transcription ${ }^{49}$. A similar repression mechanism may exist in the induction process of melanocytic differentiation by MITF in some cell lines. Indeed, trans-activation of the fibroblast tyrosinase gene has been shown to depend on the absence of a putative 'extinguisher gene $^{48-50}$, which presumably is responsible for the extinction of pigmentation in somatic cell hybrids between melanoma cells and non-pigment cells such as sublines of L cells, NCTC 2555 cells, and hepatoma cells $s^{50-53}$. Success or failure of induction of tyrosinase by MITF in several cell lines in this study may depend on the expression level of the extinguisher gene or similar repression genes. Alternatively, melanocytic differenti- tion may require a factor which promotes TRP2 expression or the constitutive expression of TRP2 itself. The finding that a subset of WS2 families do not map to the $M I T F$ gene ${ }^{54}$ may suggest the involvement of other genes in melanocyte differentiation.

Transcription factors with bHLH motifs are associated with cell fate determination in vertebrates $22,23,55,56$ and invertebrates ${ }^{57-59}$. Some proteins with bHLH-Zip motif are likely to have similar functions. For example, ADD1 is associated with adipocyte determination and differentiation $^{24}$. Our data show a link between expression of MITF and melanocyte differentiation. We have previously shown that the mutated MITF gene found in affected members of two WS2 families cannot trans-activate the tyrosinase promoter ${ }^{19}$. These data are consistent with the concept that loss-of-function mutations in the $M I T F$ gene causes the failure of such differentiation, leading to the WS2 phenotype.

\section{Methods}

Transfections. NIH/3T3 cells were transfected with varying amounts $(0.01$ to $1.0 \mu \mathrm{g})$ of the eukaryotic expression vector pCEV27 (ref. 25) or pCEV27 containing, either human MITF cDNA (melanocyte-specific isoform ${ }^{1}$ ) cloned from a melanocyte cDNA library ${ }^{20}$, ost $\mathrm{cDNA}^{34}$, c-sis cDNA or TFE3 $\mathrm{cDNA}^{35}$ (a gift of T. Kadesh) as described ${ }^{60}$. Stable transfectants were selected for G418-resistance. For the cloning of cell lines, standard dilution method ${ }^{39}$ was used.

Detection of melanogenic marker proteins. For immunocytochemical analyses, cells were fixed with $4 \%$ paraformaldehyde, permeabilized by $0.1 \%$ Triton X-100 in PBS containing 10\% normal goat serum, incubated with diluted antisera (1: 1,000$)$, immunostained using Vectastain $\mathrm{ABC}$ Elite kit and visualized by diaminobenzidine reaction. For immunoblot detection, lysates (15 or $40 \mu \mathrm{g}$ of protein) of NIH/3T3 transfectants were analysed on $8-16 \%$ gradient polyacrylamide gel. Following electrophoresis, gels were electroblotted to nitrocellulose membranes. The blots were probed with antisera ${ }^{31-33}$ to tyrosinase, TRP1 or TRP2 (gifts of V.J. Hearing), and the bands were visualized by chemiluminescence. These antisera detect each antigen specifically ${ }^{31-33}$. For the absorption test, antisera incubated at $4{ }^{\circ} \mathrm{C}$ overnight with each antigen $(1 \mathrm{mg} / 100 \mu \mathrm{l})$, a peptide derived from carboxy termini of mouse tyrosinase, TRP1, or TRP2, was used. For the serum starvation studies, cells were seeded at a density of $1 \times 10^{3}$ cells per well in duplicate $60 \mathrm{~mm}$ culture dishes and cultured in DMEM with $10 \%$ calf serum. After $12 \mathrm{~h}$ the medium was switched to the serum starvation medium, a 1:1 mixture of DMEM and NF40 containing $5 \mu \mathrm{g} / \mathrm{ml}$ of transferrin and $10 \mathrm{mM}$ sodium selenium. At the indicated times (in h), samples were obtained and cell lysates ( $30 \mu \mathrm{g}$ protein/lane) were analysed for tyrosinase expression using western blot technique.

Detection of melanogenic marker mRNAs. For northern blot analyses, $5 \mu \mathrm{g}$ of total RNA extracted from the transfectants were electrophoresed through a formaldehyde agarose gel, transferred to nylon membranes, and hybridized with ${ }^{32}$ P-labelled probes ${ }^{61}$.

For RT-PCR amplification, total RNA was extracted from MITF-transfectants, control vector transfectants and melan-a cells using TriReagent (MRC) according to the manufacturers' instructions. Eight $\mu \mathrm{g}$ of total RNA was used for each amplification. RNA was reverse-transcribed using oligo $\mathrm{dT}_{12-18}$ as a primer and $\mathrm{RNase}^{-} \mathrm{H}^{-}$reverse transcriptase (Gibco BRL). Amplification was carried out using $10 \mathrm{pmol}$ of each primer in a reaction volume of $50 \mu \mathrm{l}$. The sets of upper and lower primers used to detect the expression of tyrosinase, TRPI and TRP2 were 5'-GGGCCCAAAT TGTACAGAGAAGC-3'/5'-C TGCCA GGAGAAGAAGGATG-3', 5'-GCCCCAACTCTGTCTTTTCTCAAT-3'/5'-GATCGGCGTTATACCTCCTTAGC-3' and 3'-GG- 
ACCGGCCCCGACTGTAATC-3'/5'-GTAGGGCAACGCAAAGGACTCAT -3 ', respectively. Samples were heated $95^{\circ} \mathrm{C}$ for $3 \mathrm{~min}$, and amplified by 40 cycles of $94^{\circ} \mathrm{C}$ for $1 \mathrm{~min}, 51^{\circ} \mathrm{C}$ for $1 \mathrm{~min}$ and $72^{\circ} \mathrm{C}$ for $1 \mathrm{~min}$, with a final extension step of $1 \mathrm{~min}$ at $72^{\circ} \mathrm{C}$. PCR products in $10 \mu \mathrm{l}$ of the reaction mixture were run on 4-20\% gradient polyacrylamide gels and stained with ethidium bromide. The molecular sizes of PCR products obtained from transfectants were the same as those obtained from melan- $a$ cells.

1. Hodgkinson, C.A. et al. Mutations at the mouse microphthalmia locus an associated with defects in a gene encoding a novel basic-helix-loop-helixassociated with defects in a gene encod
zipper protein. Cell 74, 395-404 (1993).

2. Steingrimsson, E. et al. Molecular basis of mouse microphthalmia $(\mathrm{mi})$ mutations helps explain their developmental and phenotypic consequences. Nature Genet. 8, 256-263 (1994)

3. Silvers, W.K. Microphthalmia and other considerations. in The coat colors of mice. 268-332 (Springer-Verlag, 1979).

4. Tachibana, M. et al. Cochlear disorder associated with melanocyte anomaly in mice with a transgenic insertional mutation. Mol. Cell. Neurosci. 3, 433-445 (1992).

5. Asher, J.H. Jr. \& Friedman,T.B. Mouse and hamster mutants as models for Waardenburg syndrome in humans. Med. Genet. 27, 618-626(1990).

6. Avias, S. Genetic heterogeneity in the Waardenburg syndrome. Birth Defects. Original Avticie Series 7, 87-101 (1971).

7. McKusick, V.A. Mendelian Inheritance in Man. 10th edn. (Johns Hopkins University Press, Baltimore, Maryland, 1992)

8. Farrer, L.A. et al. Waardenburg syndrome (WS) type lis caused by defects at multiple loci, one of which is near ALPP on chromosome 2: First report of the WS consortium. Am. J. Hum. Genet. 50, 902-913 (1992).

9. Klein, D. Historical background and evidence for dominant inheritance of the Klein-Waardenburg syrndrome (type III). Am. J. Med. Genet. 14, 231-239 (1983).

10. Shah, K.N. et al. White forelock, pigmentary disorder of inides, and long segment Hirschsprung disease; possible variant of Waardenburg syndrome. segment Hirschsprung disease,
J. Pediat. 99, 432-435 (1981).

11. Tassabehii, M. et al. Waardenburg's syndrome patients have mutations in the human homologue of the $P$ ax-3 paired box gene. Nature $355,635-636$ (1992)

12. Baldwin, C.T., Hoth, C.F., Amos, J.A., da-Silva, E.O. \& Milunsky, A. An exonic mutation in the Hup2 paired domain gene causes Waardenburg's syndrome. Nature 355, 637-638(1992)

13. Hoth, C.F., Milunsky, A., Lipsky, N., Scheffer, R., Clamen, S.K. \& Balwin, C.T. Mutations in the paired domain of the human PAX3 gene cause KleinWaardenburg syndrome (WS-III) as well as Waardenburg syndrome type (WS-I). Am. J. Hum. Genet. 52, 455-462, (1993).

14. Chalepakis, G., Goulding, M., Read, A. Strachan, T. \& Gruss, P. Molecular basis of splotch and Waardenburg Pax-3 mutations. Proc. Natt. Acad. Sci. USA 91, 3685-3689 (1994)

15. Strachan, T. \& Read, A.P. PAX genes. Curr. Opin. Genet. Dev. 4, 427-438, (1994)

16. Tassabehii, M. et al. The mutational spectrum in Waardenburg syndrome Hum. Mol. Genet. 4, 2131-2137 (1995).

17. Read, A.P. \& Newton, V. Mutations of PAX3 unlikely in Waardenburg syndrome type 2. Nature Genet. 5, 8(1993)

18. Tassabehji, M., Newton, V.E. \& Read, A.P. Waardenburg syndrome type 2 caused by mutations in the human microphthalnia (MIT) gene. Nature Genet. 8, 251-255 (1994)

19. Nobukuni, Y., Watanabe, A., Takeda, K., Skarka, H. \& Tachibana, M. Analyses of loss-of-function mutations of the MITF gene suggest that of loss-of-function mutations of the MTF gene suggest that
haploinsufficinency is a cause of Waardenburg syndrome type 2A. Am. J. haploinsufficinency is a cause
Hum. Geret $59,76-83$ (1996).

20. Tachibana, M. et al. Cloning of MITF, the human homolog of the mouse microphthalmia gene and assignment to chromosome 3p14.1-p12.3. Hum. Mol. Genet. 3, 553-557 (1994)

21. Nakashima, S., Sando, I. Takahashi, H. \& Hashida, Y. Temporal bone histopathologic findings of Waardenburg syndrome: A case report. Laryngoscope 102, 563-567 (1992)

22. Davis, R.L., Weintraub, H. \& Lassar, A.B. Expression of single transfected cDNA converts fibroblasts to myoblasts. Cell 51, 987-1000(1987)

23. Weintraub, $\mathbf{H}$. et al. The myoD gene family: Nodal pcint during specification of the muscle cell lineage. Science 261, 761-766 (1991)

24. Tontonoz, P., Kim, J.B., Graves, R.A. \& Spiegelman, B.M. ADD1: a novel helixloop-helix transcription factor associated with adipocyte determination and differentiation. Mol. Cell. Biol. 13, 4753-4759 (1993).

25. Miki, T. et at. Development of a highty efficient expression CDNA cloning system: Application to oncogene isolation. Proc. Natt. Acad. Sci. USA 88 , 5167-5171 (1991).

26. Winder, A.J. Expression of a mouse tyrosinase cDNA in $3 T 3$ Swiss mouse fibroblasts. Biochem. Biophys. Res. Comm. 178, 739-745 (1991).

27. Bouchard, B., Fulier, B.B., Vijayasaradhi, S. \& Houghton, A.N. Induction of pigmentation in mouse fibroblasts by expression of human tyrosinase CDNA. J.Exp.

28. Jainchill, J.L., Aaronson, S.A. \& Todaro, G.J. Murine sarcoma and leukemia viruses: Assay using clonal lines of contact-inhibited mouse cells. J. Virol. 4, $549-553(1969)$

29. Yokoyama, T. et al. Conserved cysteine to serine mutation in tyrosinase is responsible for the classical albino mutation in laboratory mice. Nucl. Acid Res. 18, 7293-7298(1990)

30. Hearing, V.J. \& Ekel, T.M. Mammalian tyrosinase. A comparison of tyrosine hydroxylation and melanin formation. Biochem. J. 157, 549-557 (1976).

31. Jiménez, M., Tsukamoto, K. \& Hearing, V.J. Tyrosinase from two different loci are expressed by nomal and by transfomed melanocytes. J. Biol. Chem. 266. 1147-1156(1991)

32. Jiménez, M., Maloy, W.L. \& Hearing, V.J. Specific identification of an authentic clone for mammalian tyrosinase. J. Biol. Chem. 264, 3397-3403 (1989).

\section{Acknowledgements}

We thank S.R. Tronick, E. Gershon and J. Fex for support; J.Battey, VJ. Hearing, R.S. Petralia, M. Akeson, A. Nakayama, and H. Gregg for critical reading of the manuscript; VJ. Hearing for antibodies; $T$. Kadesh for the plasmid; and S. Takayama and K. Mizuta for examination of tumour histology and electron microscopy, respectively.

Received 28 February; accepted 23 May 1996.

33. Tsukamoto, K. Jackson, I.J., Urabe, K., Montague, P.M. \& Hearing V.J. A second tyrosinase-related protein, TRP-2, is a melanogenic enzyme termed DOPAchrome tautomerase. EMBO J. 11, 519-526 (1992).

34. Horii, Y., Beeler, J.F., Sakaguchi, K., Tachibana,M.\& Mik, Y. A novel oncogene, ost, encodes a guanine nucleotide exchange factor that potentially links Rho and Rac signaling patthways. EMBOJ. 13, 4776-4786 (1994).

35. Beckmann, H., Su, L.-K. \& Kadesch, T. TFE3: a helix-loop-helix protein that activates transcription through the immunoglobulin enhancer $\mathrm{HE} 3$ motf. Genes Dev. 4, 167-179 (1990)

36. Carr, C.S. \& Sharp, P.A. A helix-loop-helix protein related to the immunoglobulin E box-binding proteins. Mol. Cell. Biol. 10, 4384-4388 (1990).

37. Zhao, G.-Q. Zhao, Q. Zhou, X. Mattei, M.-G. \& DeCrombnugghe, B. TFEC, a basic helix-loop-helix protein, forms heterodimers with TFE 3 and inhibits TFE3-dependent transcription activation. Mol. Cell. Biol. 13, 4505-4512 (1993).

38. Hemesath, T.J. et al. Microphthalmia, a critical factor in melanocyte development, defines a discrete transcription factor family. Genes Dev $\mathbf{8}$, $2770-2780$ (1994)

39. Puck, T.T. \& Marcus, P.I. A rapid method for viable cell titration and clone production with HeLa cells in tissue culture: The use of X-irradiated cells to supply conditioning factors. Proc. Natt. Acad. Sci. USA 41, 432-437 (1955).

40. Peters, T.A., Kuijpers, W., Tonnaer, E.L., van Muijen, G.N. \& Jap, P.H Distribution and features of melanocytes during inner ear development in pigmented and albino rats. Hear. Res. 85, 169-180 (1995).

41. Keithley, E.M., Ryan, A.F. \& Feldman, M.L. Cochlear degeneration in aged rats of four strains. Hear. Res. 59, 171-178(1992).

42. Bentley, N.J., Eisen, T. \& Goding. C.R. Melanocyte-specific expression of the human tyrosinase promoter. Activation by the microphthalmia gene product and role of the initiator. Mol. Cell. Biol. 14, 7996-8006 (1994)

43. Yasumoto, K. et al. Microphthalmia-associated transcription factor as a regulator for melanocyte-specific transcription of the human tyrosinase gene. Mol. Cell Biol. 14, 8058-8070 (1994)

44. Yavuzer, U. et al. The Microphthalmia gene product interacts with retinoblastoma protein in vitro and is a target for deregulation of melanocytespecific transcription. Oncogene 10, 123-134 (1995)

45 Donatien, P., Surleve-Bazeille, J.E., Thody, A.J. \& Taieb, A. Growth and differentiation of nomal human melanocytes in a TPA-free, cholera toxin-free, low serum medium and influence of keratinocyles. Arch. Dematol. Res., 285 385-392 (1993)

46 Guarini, L. et al. Modulation of the antigenic phenotype of human melanoma cells by differentiation-inducing and growth-suppressing agents. Pigment $\mathrm{Ce}$ Res. 2, 123-131 (1992).

47. Olson, E.N. et al. Molecular control of myogenesis: antagonism between growth and differentiation. Mol. Cell. Biochern. 104, 7-13(1991).

48. Thayer, M.J. \& Weintraub, H. Activation and repression of myogeriesis in somatic cell hybrids: evidence for trans-negative regulation of MyOD in primary fibroblasts. Cell 63, 23-32 (1990).

49. Woloshin, $\mathrm{P}$. et al. MSX1 inhibits myoD expression in fibroblast $x$ 10T1/2 cell hybrids. Cell 82, 611-620 (1995)

50. Powers, T.P., Shows, T.B. \& Davidson, R.L. Pigment-cell-specific gene from fibroblasts are transactivated after chromosomal transfer into melanoma cells. Mol. Cell. Biol. 14, 1179-1190(1994).

51. Davidson, R., Ephrussi, B. \& Yamamoto, K. Regulation of melanin synthesis in mammalian cells, as studiad by somatic hybridization. I. Evidence for negative control. J. Cell. Physiol. 127, 115-128(1968)

52. Davidson, R. \& Yamamoto, K. Regulation of melanin synthesis in mammalian cells, as studied by somatic hybridization. II. The level of regulation of 3,4dihydroxyphenylalanine oxidase. Proc. Natt. Acad. Sci. USA 60, 894-901 dihydrox

53. Junke, S. Persistence, suppression and re-expression of pigment formation in somatic cell hytrids between mouse melanoma cells and non-melanoma cells. J. Cell Sci. 47, 207-226 (1981).

54. Hughes, A.E., Newton, V.E., Liu, X.Z. \& Read, A.P. A gene for Waardenburg syndrome type 2 maps close to the human homologue of the microphthalmia gene at chromosome 3p12-p14.1. Nature Genet. 7, 509-512 (1994)

55. Tamura, M. \& Noda, M. Identification of a DNA sequence involved in osteoblast-specific gene expression via interaction with helix-loop-helix (HLH)-type transcription factors. J. Cell. Biol. 126, 773-782 (1994).

56. Mume, C. \& Baltimore, D. The helix-loop-helix motif: structure and function. in Transcrptional Regulations (eds S.L. McKnight \& K.R. Yamamoto) 861-879 (Cold Spring Harbor Laboratory Press, Cold Spring Harbor, New York, 1992).

57. Jarman, A.P., Grau, Y., Jan, L.Y. \& Jan, Y.N. Atonal is a proneural gene that directs chordotonal organ formation in the Drosophila peripheral nervous system. Col/73, 1307-1321 (1993).

58. Dominguez, M. \& Campuzano, S. Asense, a member of Drosophila achaetescute complex, is a proneural and neural differentiation gene. EMBO J.12, 2049-2060 (1993).

59. Guillemot, F. et al. Mammalian achaete-scute homolog 1 is required for the earty development of olfactory and autonomic neurons. Cell 75, 463-476 (1993)

60. Wigler, M. et al. Transfer of purified herpes virus thymidine kinase gene to cultured mouse cells. Cell 11, 223-232 (1977)

61. Aroca, P., Urabe,K., Kobayashi, T., Tsukamoto, K. \& Hearing, V.J. Melanin biosynthesis patterns following homonal stimulation. J. Biol. Chem. 268 25650-25655 (1993). 